\title{
Floriant et Florete, a cura di M. PROT
}

\section{Barbara Ferrari}

\section{(2) OpenEdition \\ Journals}

\section{Edizione digitale}

URL: https://journals.openedition.org/studifrancesi/43460

DOI: $10.4000 /$ studifrancesi.43460

ISSN: 2427-5856

\section{Editore}

Rosenberg \& Sellier

\section{Edizione cartacea}

Data di pubblicazione: 1 juin 2021

Paginazione: 191

ISSN: 0039-2944

\section{Notizia bibliografica digitale}

Barbara Ferrari, «Floriant et Florete, a cura di M. РRoт», Studi Francesi [Online], 193 (LXV | I) | 2021, online dal 01 juillet 2021, consultato il 15 octobre 2022. URL: http://journals.openedition.org/studifrancesi/ 43460 ; DOI: https://doi.org/10.4000/studifrancesi.43460

Questo documento è stato generato automaticamente il 15 octobre 2022.

\section{(c)}

Creative Commons - Attribuzione - Non commerciale - Non opere derivate 4.0 Internazionale - CC BYNC-ND 4.0

https://creativecommons.org/licenses/by-nc-nd/4.0/ 


\title{
Floriant et Florete, a cura di M. PROT
}

\author{
Barbara Ferrari
}

\section{NOTIZIA}

Floriant et Florete, a cura di M. PROTA, Alessandria, Edizioni dell'Orso, «Gli Orsatti. Testi per un Altro Medioevo» 43, 2019, 506 pp.

1 L'anonimo romanzo francese in couplets d'octosyllabes di Floriant et Florete, trasmesso da un unico manoscritto databile tra la fine del XIII e il primo quarto del xIV sec. (New York, Public Library, MA 122), riveste un particolare interesse per il pubblico italiano in ragione dell'ambientazione siciliana di gran parte delle avventure dei due protagonisti. È quindi più che opportuna l'iniziativa della collana «Gli Orsatti» che ne propone la prima traduzione italiana per cura di Mariateresa Prota, alla quale si devono anche l'Introduzione e le note al testo.

2 Nel saggio introduttivo (pp. 7-38), la studiosa fa il punto sulle diverse posizioni critiche in merito alla contestualizzazione del romanzo, ascritto via via all'ambiente culturale plantageneto o a quello napoletano angioino; anche l'analisi dei significativi rimandi intertestuali (segnalati puntualmente nelle note) che legano Floriant et Florete a Claris et Laris e ai romanzi di Chrétien de Troyes (soprattutto Erec et Enide e il Conte du Graal) non sembra offrire dati probanti per stabilire una collocazione cronologica dell'opera. Per avanzare una più fondata ipotesi di datazione, M. Prota prende in esame l'ambito lessicale: la presenza di alcuni elementi o riferimenti a oggetti di cultura materiale circoscrivibili nel tempo (il corz sarrazinois, la foggia dell'armatura di Floriant, il tipo di torneo a cui partecipa alla corte arturiana) le permette infatti di situare la composizione del romanzo nell'ultimo terzo del xIII secolo. Questa datazione sarebbe confermata anche da "ragioni di ordine puramente estetico" (p.19), come la combinazione di motivi epici e romanzeschi (arturiani) che caratterizza la letteratura francese del Duecento.

In merito all'autore (proveniente probabilmente dalla Francia dell'Est, come suggerisce la lingua del testo), si sottolinea l'originalità dell'ispirazione, che appare evidente tanto 
nella costruzione del personaggio di Florete, risoluta e intraprendente, in contrasto con la consuetudine cortese, quanto nella personale interpretazione dei dati leggendari legati al mito di Artù nell'Etna. La precisione delle citazioni topografiche legate alla Sicilia e al Sud della Penisola - tra cui figurano località minori difficilmente conoscibili per via indiretta (come Catona, nei pressi di Reggio Calabria, Nicosia in provincia di Enna, o Ceprano, correttamente collocata ai confini settentrionali del regno di Sicilia) e la verosimiglianza dei tempi di percorrenza indicati inducono a pensare che l'anonimo romanziere abbia effettivamente visitato i luoghi di cui fa menzione. Particolarmente suggestiva è l'ipotesi, avanzata da M. Prota, che questi facesse parte del gruppo di menestrelli che accompagnarono Guy de Dampierre, conte di Fiandra, nella spedizione che nel 1270 lo vide unirsi alla crociata contro Tunisi. Lungo la strada del ritorno, per via di terra, vennero infatti toccate tutte le località nominate nel romanzo.

4 La traduzione, in prosa, basata sul testo dell'edizione di R. Trachsler et A. Combes pubblicato a fronte (Paris, Champion Classiques, 2003), è accurata e condotta secondo il criterio della massima fedeltà possibile all'originale, al punto che $\mathrm{i}$ «casi sporadici di traduzione libera, metaforica o problematica sono opportunamente segnalati nelle note al testo» (p. 39; ma queste indicazioni in realtà sono rarissime). Il risultato soddisfa la duplice esigenza di fornire un ausilio alla comprensione del testo e di permetterne una lettura scorrevole e avvincente anche ad un pubblico di non specialisti. Il volume si chiude con i riferimenti bibliografici; data l'estensione del romanzo (8278 vv.), sarebbe stata auspicabile la presenza di un indice dei nomi di persona e di luogo per orientarsi nella narrazione e poter seguire anche percorsi alternativi alla lettura lineare. 